\title{
PERANAN DESAIN INTERIOR PERPUSTAKAAN DALAM MENUMBUHKAN MINAT PADA RUANG PERPUSTAKAAN
}

\author{
Resti Noviani ${ }^{1}$, Agus Rusmana ${ }^{2}$, Saleha Rodiah ${ }^{3}$ \\ ${ }^{1}$ Bank OCBC NISP ${ }^{2,3}$ Program Studi Ilmu Perpustakaan Universitas Padjadjaran \\ ${ }^{1}$ restinoviani@ rocketmail.com, ${ }^{2}$ agus.rusmana@unpad.ac.id, ${ }^{3}$ saleha.rodiah@unpad.ac.id
}

\begin{abstract}
The purpose of this research was to determine the role of space, furniture and accessories, colors, lighting and air circulation in growing interest to $G$ oethe Institut B andung library's room. The method used is quantitative. The population in this study are all members of the library throughout the Goethe Institut Bandung. Sampling used in this research is purposive sam-pling with a sample size of 60 people. The location of this research is the Goethe Institut Bandung Library. The analytical method used in this research is categories analysis and cross tabulation analysis. The results of this research indicate that the library space was instrumental in growing interest to the library's room. The furniture and accessories of the library was instrumental in growing interest to library's room. The colors used in the library quite instrumental in growing interest to library's room. The lighting in the library was instrumental in growing interest to library's room. Air Circulation in the library space was instrumental in growing interest to library's room
\end{abstract}

Keywords: Interior design, interest to the library's room, the library, Goethe Institut Bandung Library

ABSTRAK - Tujuan dari penelitian ini adalah untuk mengetahui peran ruang, furnitur dan aksesori, warna, pencahayaan dan sirkulasi udara dalam menumbuhkan minat ke perpustakaan Goethe Institut Bandung. Metode yang digunakan adalah kuantitatif. Populasi dalam penelitian ini adalah seluruh anggota perpustakaan di Goethe Institut Bandung. Sampling yang digunakan da- lam penelitian ini adalah purposive sampling deng- an jumlah sampel 60 orang. Lokasi penelitian ini adalah Perpustakaan Goethe Institut Bandung. Metode analisis yang digunakan dalam penelitian ini adalah analisis kategori dan analisis tabulasi silang. Hasil penelitian ini menunjukkan bahwa ruang perpustakaan berperan penting dalam me- numbuhkan minat ke perpustakaan. Furnitur dan aksesori dari perpustakaan berperan penting da- lam menumbuhkan minat ke perpustakaan. War- na-warna yang digunakan di perpustakaan cukup berperan dalam meningkatkan minat ke perpustakaan. Pencahayaan di perpustakaan berperan penting dalam menumbuhkan minat ke perpustakaan. Sirkulasi udara di ruang perpustakaan berperan penting dalam menumbuhkan minat ke perpustakaan.
Kata Kunci: Desain Interior, Minat ke Perpustakaan, Perpustakaan, Goethe Institut Bandung Library

PENDAHULUAN

Pada saat ini pengembangan perpustakaan di Indonesia masih menghadapi banyak hambatan dan rintangan. Secara umum masalah yang sering dijumpai adalah masih kurangnya jumlah pemustaka yang datang dan melakukan kegiatan di perpustakaan seperti membaca buku atau mengerjakan tugas di perpustakaan. Persoalan ini berkaitan dengan fasilitas fisik perpustakaan seperti gedung perpustakaan. Persoalan pengembangan fisik perpustakaan tidak hanya pada gedung saja, tetapi juga terkait dengan sisi kegunaan dan estetika dari perpustakaanya itu sendiri.

Perpustakaan memiliki fungsi dan peranan yang sangat penting bagi setiap pemus- takanya. Selain harus memberikan layanan terbaik, sebuah perpustakaan juga harus didukung dengan tempat yang nyaman dan menyenangkan, sehingga setiap pemustaka akan berminat dan se- ring berkunjung ke perpustakaan. Untuk itu, agar dapat menarik perhatian pemustaka sebuah perpustakaan haruslah membangun citra yang baik bagi pemustakanya. Faktor pembentuk citra yang baik dalam perpustakan sendiri adalah kinerja pelayanan dari pegawai atau pustakawan dari 
perpustakaan tersebut, serta dengan adanya dukungan dari fasilitas, perabotan, dan peralatan yang terdapat di dalamnya guna menunjang kenyamanan bagi pemustaka. Suasana yang seperti itu yang bisa menarik pemustaka untuk terus kembali berkunjung dan betah berlamalama di perpustakaan.

Menurut Widodo dan Prasetyo Budi, rancangan suatu bangunan atau lingkungan yang bagus akan menyebabkan orang merasa lebih nyaman, aman dan tentunya membuat orang yang berada di dalamnya menjadi meningkat produktivitasnya dan sebaliknya rancangan yang jelek akan membuat perasaan tidak berdaya (powerless) dan menimbulkan stress (dalam studi terdahulu Fakhrunnisa 2011). Sedangkan menurut Metcalf (1965, 6) "ruangan dalam sebuah gedung perpustakan harusnya dirancang senyaman mung- kin, karena hal ini sangat berpengaruh pada kondisi pisikologi orang yang berada di dalamnya". Demikian juga dengan suatu rancangan perpustakaan. Suatu rancangan perpustakaan yang baik, akan menyebabkan pengunjung per- pustakaan merasa nyaman, aman dan produktif.

Desain interior merupakan salah satu hal yang cukup penting dalam rancangan su atu bangunan, khususnya dalam hal ini adalah pembangunan perpustakaan. Perpustakaan yang baik dalam perencanaan gedung dan ruang perpustakaannya perlu memperhatikan fungsi tiap ruang, unsur-unsur keharmonisan dan keindahan, baik dari segi interior dan eksterior. Ruang perpustakaan akan nyaman bagi pemakai apabila ditata dengan memperhatikan fungsi, keindahan, dan keharmonisan ruang. Dengan demikian pengaruh desain interior terhadap kenyamanan membaca akan memberikan manfaat apabila desain interior perpustakaan dapat disesuaikan dengan kebutuhan dan keinginan pemustaka.

Begitu pula dengan perpustakaan khusus, dimana perpustakaan khusus harus dapat memberikan kebutuhan informasi bagi para pemustaka yang membutuhkannya. Keberadaan sebuah perpustakaan khusus di lingkungan masyarakat diharapkan dapat meningkatkan mutu pendidikan masyarakat sekitar. Pemilihan desain interior yang menarik di perpustakaan diharapkan dapat menarik perhatian para pemustaka untuk sering berkunjung ke perpustakaan. Tidak hanya untuk kenyamanan pemustaka yang memang gemar berkunjung ke perpustakaan, tetapi desain interior perpustakaan yang menarik juga diperuntukan agar dapat menarik pengguna yang sebelumnya enggan datang ke perpustakaan menjadi senang untuk datang ke perpustakaan. Pemustaka yang memang gemar pun menjadi semakin nyaman berada di dalam perpustakaan sehingga pemustaka tidak akan merasa cepat bosan ketika berada di perpustakaan.

Perpustakaan khusus Goethe Institut Bandung merupakan perpustakaan khusus yang menyediakan segala informasi yang berkaitan dengan negara Jerman. Perpustakaan ini merupakan bagian dari lembaga kursus bahasa dan kebudayaan Jerman yang lokasinya berada di Jakarta dan Bandung. Pada awal Bulan April 2016 perpustakaan Goethe Institut yang berlokasi di Bandung telah resmi di buka kembali karena telah selesainya proses renovasi selama dua 
bulan. Perpustakaan tersebut telah didesain ulang dengan semua barang-barang baru. Perpustakaan ini di desain menjadi perpustakaan yang modern, minimalis, penuh warna dan menarik. Desain interior dari perpustakaan ini pun dilengkapi dengan meja-meja dan kursi-kursi di ruang baca yang nyaman yang diharapkan dapat mendukung konsentrasi belajar serta dilengkapai sesi permainan yang riang dan damai. Terdapat pula pojok ruangan yang nyaman dengan sebuah kotak buku dan kursi beanbag cocok untuk usia anakanak dan remaja. Tata letak ruang dan cahaya yang juga mendukung kesan perpustakaan yang modern minimalis akan meningkatkan ting- kat kenyamanan bagi pemustakanya.

Melalui visualisasi modern dan kontemporer, mebel yang ergonomik, serta alat proyeksi leng- kap dengan soundsystem yang modern akan menjadikan fungsi perpustakaan di masa men- datang menjadi berbeda yaitu sebagai tempat untuk rapat, seminar juga acara lainnya. Menurut wakil direktur Goethe Institut Bandung yaitu Thomas Freundorfer "Perpustakaan baru di Goe- the Institut Bandung merupakan tempat yang nyaman bagi pengunjung terutama bagi mereka yang mencari informasi dan hiburan yang berkenaan dengan Jerman dan Indonesia" (https://www.goethe.de/ins/id/id/ver.cfm?fuseacti on=events.detail\& event_id=20726177).

Lokasi perpustakaan Goethe Institut yang berada di pusat kota telah menarik minat banyak orang yang memang tertarik dengan negara Jerman untuk menjadi anggota. Kemudahan akses, kelengkapan koleksi mengenai negara Jerman, suasana yang nyaman, dan keunikan yang dimiliki oleh perpustakaan Goethe Institut diharapkan dapat membuat pengunjung betah berlama-lama dan ingin terus berkunjung kembali ke perpustakaan.

Setelah peneliti melakukan pra-penelitian di Perpustakaan Goethe Institut, peneliti menemukan hal yang menarik dari perpustakaan ini antara lain, desain interior perpustakaan yang kini memiliki konsep modern minimalis dan memiliki koleksi yang sangat lengkap mengenai bahasa dan kebudayaan Jerman, karena kebanyakan perpustakaan khusus yang ada disekitar Bandung belum menerapkan desain interior yang serupa.

Dari hal tersebut dapat dilihat bahwa ada aspek yang menarik untuk diteliti terutama mengenai desain interior dengan pemanfaatan ruang perpustakaan oleh pengguna. Alasan peneliti melakukan penelitian di ruang perpustakaan yaitu karena ingin melihat apakah anggota dari perpustakaan tersebut akan lebih berminat untuk datang dan melakukan kegiatan di dalam ruang perpustakaan. Hal ini karena dilihat dari segi tata ruang dan desain interior ruang perpustakaan Goethe Institut yang baru memiliki desain yang cukup menarik dan unik yang diduga dapat menumbuhkan minat anggota untuk sering datang ke perpustakaan Goethe dan berlama-lama melakukan aktivitas dan memanfaatkan fasilitasnya disana.

\section{TINJAUAN PUSTAKA}

Salah satu faktor yang dapat membuat perpustakaan menjadi menarik yaitu desain interior dari ruangan perpustakaan. Desain interior perpustakaan dirancang sedemikian rupa 
agar dapat menarik pemustaka untuk memanfaatkan fasilitas yang tersedia dalam ruangan. Desain interior dan manusia terjadi interaksi, dimana desain befungsi sebagai alat yang menjembatanai antara perpustakaan dengan penggunanya.

Desain interior ruangan yang baik menurut Ching (1996, 160) yaitu:

Desain interior dalam bangunan dibentuk oleh elemen-elemen yang bersifat arsitektur dari struktur pembentukannya yang terdiri atas ru- angan, warna, cahaya, akustik suara, sirkulasi udara, aksesoris dan perabotan. Elemen-elemen tersebut membutuhkan pengembangan dengan cara memanipulasi elemen-elemen tersebut men- jadi pola-pola spasial, visual dan sensori sehing- ga memperindah suatu ruangan dan membuatnya dapat dihuni.

Dilihat dari para pendapat ahli mengenai desain interior ruang perpustakaan dan disesuaikan dengan kebutuhan penelitian maka unsur dari desain interior perpustakaan Goethe Institut meliputi: ruang, warna, pencahayaan, pemilihan dan penempatan perabotan dan sirkulasi udara. Sehingga akan menimbulkan efek bahwa dengan adanya desain interior ini akan menarik minat pengguna untuk memanfaatkan ruang perpustakaan.

Menurut Abror $(1993,112)$

minat atau interest bisa berhubungan dengan gaya gerak yang mendorong kita cenderung atau merasa tertarik pada orang, benda atau kegiatan ataupun bisa berupa pengalaman yang efektif yang dirangsang oleh kegiatan itu sendiri.

Dengan kata lain, minat dapat menjadi penyebab kegiatan dan penyebab partisipasi da- lam kegiatan. Minat muncul apabila individu tersebut terhadap sesuatu yang dirasakan menarik dan bermakna serta dibutuhkan oleh individu.

Menurut Abror $(1993,112)$ bahwa minat mengandung unsur-unsur :

a)Kognisi (mengenal)

Minat itu didahului oleh pengetahuan dan informasi mengenai obyek yang dituju oleh minat tersebut.

b)Emosi (perasaan)

Unsur emosi, karena dalam partisipasi atau pengalaman itu disertai dengan perasaan tertentu (biasanya perasaan senang).

c) Konasi (kehendak)

Merupakan kelanjutan dari kedua unsur tersebut yaitu yang diwujudkan dalam bentuk kemauan dan hasrat untuk melakukan suatu kegiatan.

Hal ini sesuai dengan minat anggota untuk melakukan aktivitas di ruang perpustakaan yang interiornya telah didesain menjadi lebih menarik. Anggota yang berminat akan memiliki perasaan senang terhadap desain interior dan berkehendak untuk melakukan kegiatan di ruang perpustakaan Goethe Institut seperti membaca buku atau mengerjakan tugas.

Kesesuaian desain interior ruang perpustakaan dalam menarik minat untuk berkegiatan di ruang perpustakaan ini sesuai dengan apa yang dikemukakan oleh Francis D.K Ching yaitu, Desain interior dapat memenuhi kebutuhan dasar kita akan sarana untuk bernaung dan berlindung, menentukan langkah sekaligus mengatur bentuk aktivitas kita, memelihara aspirasi kita dan mengekspresikan ide-ide yang menyertai segala tindakan kita, mempengaruhi penampilan, perasaan dan kepribadian kita. Oleh sebab itu, maksud dan tujuan desain interior adalah untuk memperbaiki fungsi, memperkaya nilai estetika 
dan meningkatkan aspek psikologis dari ruang interior (Ching 1996, 46).

Dilihat dari pendapat diatas, desain interior yang elemen-elemennya meliputi ruang, warna, pencaha- yaan, sirkulasi udara serta perabotan dan aksesoris yang dapat memenuhi kebutuhan dasar seseorang akan sarana untuk bernaung, menentukan langkah sekaligus mengatur bentuk aktivitas, memelihara aspirasi dan mengekspresikan ide-ide yang menyertai segala tindakan kita, mempengaruhi penampilang, perasaan dan ke- pribadian seseorang. Hal ini juga dapat diterje- mahkan bahwa sebuah desain interior yang dirancang dengan baik dan menarik dapat me- narik minat seseorang untuk menggunakan ru- angan yang telah dirancang tersebut. Minat seseorang merupakan sisi psikologis dari seorang manusia. Sesuai dengan yang dijelaskan oleh Abror $(1993,112)$ yaitu minat merupakan rasa tertarik seseorang terhadap sesuatu.

Dengan adanya penerapan desain interior pada perpustakaan, perpustakaan pun akan terlihat menarik dan sesuai dengan kebutuhan lingkungannya. Maka dari itu, sebuah perpustakaan dapat menerapkan desain interior sebagai pendorong manusia untuk menjadi minat terhadap perpustakaan sehingga membuat seseorang menjadi sering ingin berkunjung ke perpustakaan lalu melakukan aktivitasnya di ruang perpustakaan. Desain interior perpustakaan pun dapat membuat pengguna senang dan merasa puas dengan desain interiornya sehingga membuat pengguna merasa nyaman sehingga ingin sering berlama-lama melakukan aktivitas di ruang perpustakaan.

\section{METODE PENELITIAN}

Metode penelitian yang digunakan dalam penelitian ini adalah metode survei. Metode yang digunakan untuk mendeskripsikan mengenai bagaimana pengembangan desain interior dalam menumbuhkan minat anggota pada ruang perpustakaan oleh anggota melalui data. Menurut Singarimbun dan Effendi 1989, 3 menyatakan bahwa:

Dalam survai, informasi dikumpulkan dari responden dengan menggunakan kuestioner. Umumnya pengertian survei dibatasi pada penelitian yang datanya dikumpulkan dari sampel atas populasi untuk mewakili seluruh populasi. Berbeda dengan sensus yang informasinya dikumpulkan dari seluruh populasi.

Dengan demikian penelitian survei adalah penelitian yang mengambil sampel dari satu populasi dan menggunakan kuesioner sebagai alat pengumpulan data yang pokok.

\section{RUMUSAN MASALAH}

Berdasarkan pendahuluan diatas maka rumusan masalah dalam penelitian ini adalah "Bagaimana Peranan Desain Interior Perpustakaan dalam Menumbuhkan Minat Pada Ruang Perpustakaan?" sehingga diperlukan penelitian untuk menjawab pertanyaan tersebut.

Identifikasi masalah yang berupa pertanyaan penelitian dari penelitian ini adalah: Bagaimana peranan ruang perpustakaan dalam menumbuhkan minat pada ruang perpustakaan?; (2) Bagaimana peranan perabotan dan aksesoris perpustakaan dalam menumbuhkan minat pada ruang perpustakaan?; (3) Bagaimana peranan 
warna perpustakaan dalam menumbuhkan minat pada ruang perpustakaan?; (4) Bagaimana peranan pencahayaan perpustakaan dalam menumbuhkan minat pada ruang perpustakaan?; (5) Bagaimana peranan sirkulasi udara perpustakaan dalam menumbuhkan minat pada ruang perpustakaan?

\section{HASIL DAN PEMBAHASAN}

\section{Karakteristik Responden}

Hasil penelitian ini menunjukkan mayoritas responden pada penelitian ini adalah wanita sebanyak 40 orang $(66,7 \%)$, berusia $17-22$ tahun sebanyak 37 orang $(61,7 \%)$ dan merupakan pelajar/mahasiswa sebanyak 52 orang $(86,7 \%)$.

\section{Tanggapan pada Ruang}

Data pada hasil penelitian menunjukkan mayoritas responden penelitiam sebanyak 34 orang $(56,7 \%)$ menyatakan setuju bahwa luas ruangan perpustakaan membuat leluasa untuk beraktivitas, sebanyak 34 orang $(56,7 \%)$ menyatakan sangat setuju bahwa tinggi ruangan perpustakaan tidak meninggalkan kesan sumpek dan sebanyak 34 orang $(56,7 \%)$ menyatakan setuju bahwa bentuk ruangan perpustakaan sesuai untuk digunakan beraktivitas.

\section{Tanggapan pada Perabotan dan Aksesoris}

Data pada hasil penelitian menunjukkan mayo- ritas responden penelitian sebanyak 41 orang $(68,3 \%)$ menyatakan tidak setuju bahwa ukuran kursi dan meja belum sesuai dengan kondisi ruangan, sebanyak 40 orang $(66,7 \%)$ menyatakan setuju bahwa ukuran rak tidak membuat raungan menjadi sempit, sebanyak 42 orang (70\%) menyatakan setuju bahwa ukuran sofa dan kursi beanbag sesuai dengan ruangan, sebanyak 34 orang $(56,7 \%)$ menyatakan setuju bahwa penempatan kursi dan meja membuat leluasa bergerak, sebanyak 34 orang $(56,7 \%)$ menyatakan setuju bahwa penempatan rak memudahkan pencarian pengambilan koleksi, sebanyak 35 orang $(58,3 \%)$ menyatakan setuju bahwa penempatan sofa dan kursi beanbag sudah tertata dengan tepat, sebanyak 38 orang $(63,3 \%)$ menyatakan setuju bahwa penempatan aksesoris sesuai dan membuat ruangan lebih menarik, sebanyak 41 orang $(68,3 \%)$ menyatakan setuju bahwa penempatan alat-alat elektronik sudah tertata dengan baik, sebanyak 31 orang $(51,7 \%)$ menyatakan sangat setuju bahwa model kursi dan meja membuat ruangan menjadi lebih menarik, sebanyak 30 orang $(50 \%)$ menyatakan sangat setuju bahwa model rak koleksi membuat ruangan terlihat modern dan menarik, dan sebanyak 32 orang $(53,3 \%)$ menyatakan setuju bahwa model sofa dan kursi beanbag menimbulkan kesan santai.

\section{Tanggapan pada Warna}

Data pada hasil penelitian menunjukkan mayoritas responden penelitian sebanyak 32 orang $(53,3 \%)$ menyatakan setuju bahwa warna yang dipilih tidak menimbulkan kesan suram, sebanyak 37 orang $(61,7 \%)$ menyatakan tidak setuju bahwa warna yang digunakan pada perabotan dan fasilitas terlalu mencolok, dan sebanyak 33 orang (55\%) menyatakan setuju bahwa warna dalam ruangan memberikan kesan nyaman dan harmonis.

\section{Tanggapan pada Pencahayaan}


Data pada hasil penelitian menunjukkan mayor- itas responden penelitian sebanyak 36 orang $(60 \%)$ menyatakan setuju bahwa warna cahaya lampu sesuai dengan kondisi ruangan, sebanyak 34 orang $(31,7 \%)$ menyatakan setuju bahwa porsi sinar lampu sesuai untuk kepentingan membaca, sebanyak 32 orang $(53,3 \%)$ menyatakan setuju bahwa pemilihan jenis lampu memberi kesan modern dan menarik dan se- banyak 44 orang $(73,3 \%)$ menyatakan setuju bahwa posisi penempatan sumber cahaya tepat untuk beraktivitas.

\section{Tanggapan pada Sirkulasi Udara}

Data pada hasil penelitian menunjukkan mayoritas responden penelitian sebanyak 41 orang $(68,3 \%)$ menyatakan setuju bahwa pengaturan suhu udara membuat merasa nyaman dan sebanyak 43 orang $(71,7 \%)$ menyatakan setuju bahwa udara dalam ruangan segar saat terhirup.

\section{Tanggapan pada Minat Pada Ruang}

\section{Perpustakaan}

Data pada hasil penelitian menunjukkan mayoritas responden penelitian sebanyak 27 orang $(45 \%)$ menyatakan setuju bahwa mereka mengetahui perubahan desain interior yang telah diperbaharui, sebanyak 32 orang $(53,3 \%)$ menyatakan sangat setuju bahwa mereka merasa senang dan menyukai desain interior perpustakaan, sebanyak 30 orang (50\%) menyatakan sangat setuju bahwa mereka merasa nyaman dengan desain interior perpustakaan, sebanyak 31 orang $(51,7 \%)$ menyatakan setuju bahwa mereka berkeinginan untuk sering berkunjung jika memilii waktu luang, sebanyak 29 orang $(48,3 \%)$ menyatakan setuju bahwa mereka berkeinginan untuk sering beraktivitas di dalam perpustakaan, sebanyak 29 orang $(48,3 \%)$ menyatakan sangat setuju bahwa mereka berkeinginan untuk sering memanfaatakan fasilitas perpustakaan, dan sebanyak 30 orang (50\%) menyatakan setuju bahwa mereka merasa nyaman sehingga ingin sering berlama-lama di perpustakaan.

\section{Hasil Analisis Tabulasi Silang}

1.Hasil analisis tabulasi silang menunjukkan tanggapan pada ruang perpustakaan pada kategori tinggi dan minat pada ruang perpustakaan sebagai sarana berkegiatan pada kategori tinggi sebanyak 51 orang (85\%). Hal ini berarti ruang perpustakaan sangat berperan dalam menumbuhkan minat anggota pada ruang perpustakaan. Hasil analisis tabulasi silang menunjukkan mayoritas tanggapan pada perabotan dan aksesoris ruang perpustakaan pada kategori tinggi dan minat pada ruang perpustakaan sebagai sarana berke- giatan pada kategori tinggi sebanyak 50 orang $(83,3 \%)$. Hal ini berarti perabotan dan aksesoris sangat berperan dalam menumbuhkan minat anggota pada ruang perpustakaan.

2.Hasil analisis tabulasi silang menunjukkan mayoritas tanggapan pada warna perpustakaan pada kategori sedang dan minat pada ruang perpustakaan sebagai sarana berkegiatan pada kategori tinggi sebanyak 38 orang $(63,3 \%)$. Hal ini berarti warna perpustakaan cukup berperan dalam menumbuhkan minat anggota pada ruang perpustakaan.

3.Hasil analisis tabulasi silang menunjukkan mayoritas tanggapan pada pencahayaan ruang 
perpustakaan pada kategori tinggi dan minat pada ruang perpustakaan sebagai sarana berkegiatan pada kategori tinggi sebanyak 52 orang $(86,7 \%)$. Hal ini berarti pencahayaan pada ruang perpustakaan sangat berperan dalam menumbuhkan minat anggota pada ruang perpustakaan.

4.Hasil analisis tabulasi silang menunjukkan mayoritas tanggapan pada sirkulasi udara perpustakaan pada kategori tinggi dan minat pada ruang perpustakaan sebagai sarana berkegiatan pada kate- gori tinggi sebanyak 47 orang $(78,3 \%)$. Hal ini berarti sirkulasi udara ruang perpustakaan sangat berperan dalam menumbuhkan minat anggota pada ruang perpustakaan.

\section{SIMPULAN}

Ruang perpustakaan sangat berperan dalam menumbuhkan minat anggota untuk berkegiatan di ruang perpustakaan. Ruang Perpustakaan Goethe Institut Bandung yang telah dibangun sedemikian rupa sudah sesuai dengan harapan pengguna untuk melakukan berbagai aktivitasnya.

Perabotan dan aksesoris yang digunakan pada perpustakaan sangat berperan dalam menumbuhkan minat anggota untuk berkegiatan di ruang perpustakaan. Perabotan dan aksesoris yang digunakan pada ruang Perpustakaan Goethe Institut Bandung sudah sesuai dengan harapan pengguna untuk melakukan berbagai aktivitasnya.

Warna yang digunakan pada ruang perpustakaan cukup berperan dalam menum- buhkan minat anggota untuk berkegiatan di ruang perpustakaan. Warna yang digunakan pada ruang Perpustakaan Goethe Institut Bandung sudah cukup sesuai dengan harapan pengguna untuk melakukan berbagai aktivitasnya.

Pencahayaan pada ruang perpustakaan sangat berperan dalam menumbuhkan minat anggota untuk berkegiatan di ruang perpustakaan Pencahayaan pada ruang Perpustakaan Goethe Institut Bandung sudah sesuai dengan harapan pengguna untuk melakukan berbagai aktivitasnya.

Sirkulasi udara pada ruang perpustakaan sangat berperan dalam menumbuhkan minat anggota untuk berkegiatan di ruang perpustakaan. Sirkulasi udara pada ruang Perpustakaan Goethe Institut Bandung sudah sesuai dengan harapan pengguna untuk melakukan berbagai aktivitasnya.

\section{DAFTAR PUSTAKA}

Abror, Abd. Rachman. (1993). Psikologi Pendidikan. Yogyakarta: Nur Cahya. Bungin, Burhan. (2011). Metodologi Penelitian Kuantitatif. Jakarta : Kencana.

Basuki, Sulistyo. (1993). Pengantar Ilmu Perpustakaan. Jakarta: Gramedia Pustaka Utama.

Ching, D.K Francis. (1996). Ilustrasi Desain Interior. Jakarta: Erlangga.

Fakhrunnisa, Hanna Farhah. (2015). "Hubungan Desain Interior Dengan Pemanfaatan Ruang Baca (Study Carrel) oleh Pengguna".

Goethe Institut Indonesia. 2016. ModernMenarik- Penuh Warna- Mengajak. 
https://www.goethe.de/ins/id/id/ver.cfm?fuse

action=events.detail\&event_id=20726177.

Diakses pada tanggal 27 April 2016.

Haris, M. Cryril. (1993). Dictionary of Building

Construction Material and Method, ed $2^{\text {nd }}$.

H.S. Lasa. (2005). Manajemen Perpustakaan.

Yogyakarta: Gama Media.

http://journal.unair.ac.id/download-fullpapers-

Jurnal\%20Adrina.pdf. Dipublikasikan oleh

Universitas Airlangga. Diakses pada tanggal

27 April 2016.

Metcalf. Keyes D. (1965). Planning Academic

And Research Library Building. New York:

Mcgraw-Hill.

Pile, John. F. (1997). Interior Design. New York:

Harry N. Abrams Inc

Rakhmat, Jalaluddin. (2004). Metode Penelitian

Komunikasi: Dilengkapi Dengan Contoh

Analisis Statistik. Bandung: PT Remaja

Rosdakarya.

Sugiyono. (2014). Metode Penelitian Kuantitatif,

Kualitatif dan R\&D. Bandung: Alfabeta.

Sutarno, (2003). Perpustakaan dan Masyarakat.

Ed. 1. Jakarta: Yayasan Obor Indonesia.

Sutarno, NS. (2006). Perpustakaan dan

Masyarakat. Jakarta: Sagung Seto.

Yusuf, Pawit M. (2010). Komunikasi

Instruktusional : Teori dan Praktik. Jakarta:

Bumi Aksara. 
